\title{
EFFECTS OF UV, HUMIDITY, AND HIGH TEMPERATURE EXPOSURE ON
} LINEN FIBERS

\author{
IRINA SANDULACHE ${ }^{1}$, MIHAELA-CRISTINA LITE ${ }^{1,2}$, LUCIA-OANA SECAREANU ${ }^{1}$, \\ ELENA-CORNELIA MITRAN ${ }^{1,2}$, OVIDIU IORDACHE ${ }^{1}$, ELENA PERDUM $^{1}$ \\ ${ }^{1}$ The National R\&D Institute for Textiles and Leather Bucharest (INCDTP), 16 Lucretiu \\ Patrascanu, 030508, Bucharest, Romania, office@incdtp.ro \\ ${ }^{2}$ University Politehnica of Bucharest, Faculty of Applied Chemistry and Materials Science, 1-7 \\ Gheorghe Polizu, Bucharest, Romania, secretariat@chimie.upb.ro
}

\begin{abstract}
Generally, the most common damaging factors for linen textile materials are the environmental conditions, their handling, and natural decay. Such environmental factors are ultraviolet (UV) radiation, humidity, and high temperature. Therefore, to investigate the effects these factors may cause, an accelerated weathering test was conducted on linen fabrics, using alternating cycles of UV exposure and humidity, along with relatively high temperatures. The effects of this test were investigated using non-destructive and micro-destructive analysis techniques. Scanning Electron Microscopy (SEM) was used to observe any modifications appearing at the surface of the fibers Energy Dispersive X-Ray Analysis (EDS) was employed in conjunction with SEM for obtaining the spectrum of the chemical elements that were present at the surface of the linen samples. The modifications of functional groups occurring due to the weathering of linen were assessed by Fourier-Transform Infrared Spectroscopy (FT-IR). The color change of the samples was measured with a spectrophotometer. All the acquired information can be used as a starting point for the development of customized environmental parameters for keeping patrimony linen fabrics in museums in optimum conditions, thus preventing further damage. Additionally, the artificially weathered fabrics will be further employed in conservation experiments as substitute for old linen fabrics.
\end{abstract}

Keywords: linen, weathering, textiles

\section{INTRODUCTION}

Textiles have been, for a long time, a significant part of the essential necessities of humankind. The use of textiles commenced with natural fibers of animal and vegetal origin.

There are evidences of the use of linen fibers from more than 30000 years ago and it is still being valued due to its properties. There are many historically significant linen textiles that are currently found in museums nowadays.

Linen is a bast fiber, meaning that it originates from the inner part of the flax plant stem (Linum usitatissimum) (Akin, 2003). The fibers have a diameter of approx. $15-17$ $\mu \mathrm{m}$ and a clockwise rotation around the longitudinal axis (Markova, 2019). The chemical composition of linen fibers is approx. $71 \%$ cellulose, $18.6-20.6$ hemicellulose, $2.2 \%$ lignin, and 1.5\% waxes (Friedrich and Breuer, 2015).

\section{MATERIALS AND METHODS}

For developing the present work, an undyed linen fabric has been used. The fabric has been divided into six $11 \times 9 \mathrm{~cm}$ rectangles. One of the rectangles has been kept as a control sample. The other five fabric rectangles have been submitted to an accelerated weathering process inside an accelerated weathering tester (QUV, Q-Lab). The following weathering method was employed: an $8 \mathrm{~h} \mathrm{UV}$ exposure cycle at $70^{\circ} \mathrm{C}$ using fluorescent UVB-313 lamps, followed by a $4 \mathrm{~h}$ condensation cycle (60\% humidity) at 
$50^{\circ} \mathrm{C}$. One sample has been collected every three days, the final sample being collected after fifteen days of weathering. The total UV and humidity exposure time for each sample is presented in the following table:

Table 1. UV radiation and humidity exposure time of the linen samples

\begin{tabular}{ccc}
\hline Sample & UV time $(\mathrm{h})$ & Humidity time $(\mathrm{h})$ \\
\hline t0 (control) & 0 & 0 \\
t1 & 48 & 24 \\
t2 & 96 & 48 \\
t3 & 144 & 72 \\
t4 & 192 & 96 \\
t5 & 240 & 120 \\
\hline
\end{tabular}

A Nicolet iS50 (ThermoFisher) Fourier-transform infrared spectroscope (FT-IR) with an attenuated total reflection (ATR) accessory was used to investigate the modifications of the functional groups over a spectral range of $4000-400 \mathrm{~cm}^{-1}$.

A FEI Quanta 200 scanning electron microscope (SEM) has been employed is for assessing the morphology of the linen fibers. An Element energy-dispersive X-ray spectroscopy detector (EDS) from EDAX-AMETEK was used in conjunction with the previously mentioned SEM in order to determine the elemental composition of the samples.

The chromatic parameters have been measured with a Datacolor spectrophotometer.

\section{RESULTS AND DISCUSSION}

\section{FT-IR}

The results for all samples are presented in Figure 1:

Linen

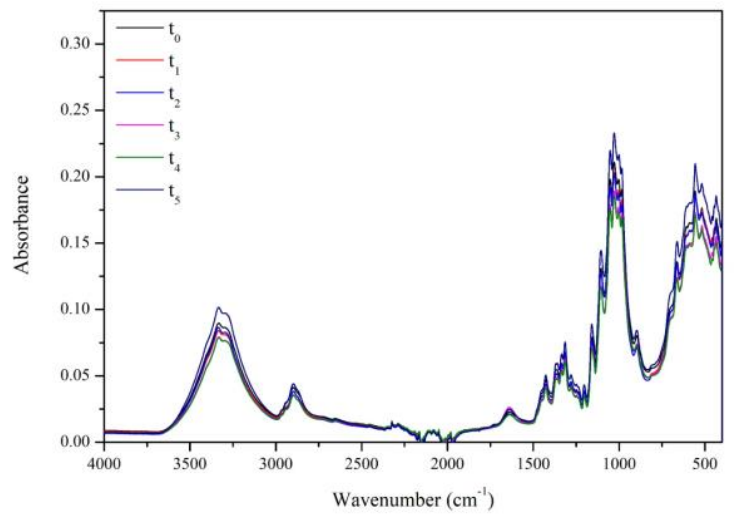

Figure 1. Overlapped FT-IR spectra of the linen samples

The structural differences between the samples were minimal. None of the samples presented new IR absorption bands. For all the samples, the IR spectra corresponded with the literature data (Chung, 2004). 
The specific band positions for the studied materials in this paper, compared to literature data are presented in Table 2.

Table 2. Absorption band positions in IR for the linen samples, compared to literature

\begin{tabular}{ccc}
\hline $\begin{array}{c}\text { Experimental band } \\
\text { position }\left(\mathrm{cm}^{-1}\right)\end{array}$ & $\begin{array}{c}\text { Band position reported } \\
\text { in literature }\left(\mathrm{cm}^{-1}\right)\end{array}$ & Band attribution \\
\hline $3600-3000$ & $3550-3100$ & H-bonded OH stretch \\
2897 & $2980-2800$ & C-H stretching \\
1636 & 1644 & Adsorbed $\mathrm{H}_{2} \mathrm{O}$ \\
1427 & 1429 & $\mathrm{CH}$ wagging (in-plane bending) \\
1361 & 1368 & $\mathrm{CH}$ bending (deformation stretch) \\
1334 & 1337 & OH in-plane bending \\
1314 & 1316 & CH wagging \\
1280 & 1281 & $\mathrm{CH}$ deformation stretch \\
1247 & 1247 & OH in-plane bending \\
1203 & 1203 & OH in-plane bending \\
1159 & 1160 & Asym. Bridge C-O-C \\
1105 & 1108 & Asym. Bridge C-O-C \\
1052 & 1057 & Asym. In-plane ring stretch \\
1028 & 1030 & C-O stretch \\
897 & 900 & Asym. out-of-phase ring stretch: \\
& & C 1 - O-C 4 ; b glucosidic bond \\
\hline
\end{tabular}

\section{SEM}

The modifications appearing at the surface of the linen fibers with the increasing exposure time to the accelerated weathering conditions can be observed in Figure 2.
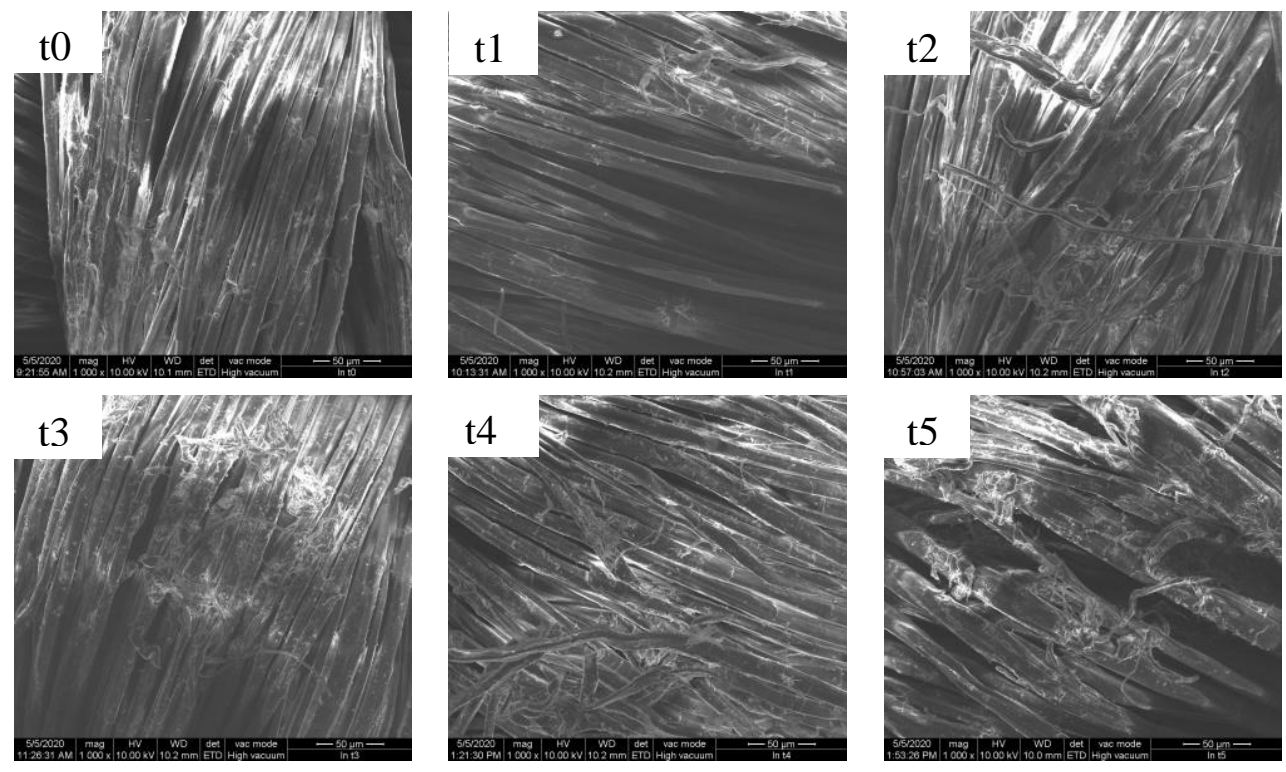

Figure 2. SEM micrographs of the control sample (t0) and the artificially aged samples $(\mathrm{t} 1-\mathrm{t} 5)$ at $1000 \times$ magnification 
With the increasing exposure time to the weathering conditions, the linen fibers have become noticeably damaged. The damage appeared as splits and ruptures, affecting the integrity of the fibers. By the time $\mathrm{t5}$, almost all the fibers were broken. These effects lead to an additional reduction of mechanical properties due to the molecular modifications that resulted from the oxidation at the glycosidic bonds as well as at hydroxyl groups of the cellulose, causing the scission of the macromolecular chains (Kouznetsov et al.,1996).

\section{EDS}

This elemental analysis method was mainly employed to quantify the variation of the oxygen/carbon ratio from the main component of the linen fibers - cellulose.

Table 3. Element quantification

\begin{tabular}{cccc}
\hline Sample & Oxygen $(\%$ weight $)$ & Carbon $(\%$ weight $)$ & O/C ratio \\
\hline t0 & 52.97 & 47.03 & 1.13 \\
t1 & 53.82 & 46.18 & 1.17 \\
t2 & 54.05 & 45.95 & 1.18 \\
t3 & 53.58 & 46.42 & 1.15 \\
t4 & 53.87 & 46.13 & 1.17 \\
t5 & 54.32 & 45.68 & 1.19 \\
\hline
\end{tabular}

A slight increase in the $\mathrm{O} / \mathrm{C}$ ratio can be observed when comparing samples t0 and $\mathrm{t} 5$, that can be attributed to oxidative transformations (i.e., aldehyde groups from the linen fibers into carboxyl groups) (Kleinert, 1972).

\section{Chromatic Parameters}

The color changes are expressed in a qualitative manner by using three variables: shade, resistance, and luminosity (Colour Terms and Definitions, 2008; Ingamells, 1993). The chromatic parameters indicate the visual differences that may appear when a textile material is aged. The parameter $\mathrm{L}^{*}$ represents the brightness of the samples, on a scale from 0 (black) to 100 (white). The $\mathrm{DL}^{*}$ parameter indicates the brightness level of the samples. The saturation $\left(\mathrm{C}^{*}\right)$ represents the intensity of a certain color. The DC* parameter measures the saturation degree of the samples.

Table 4. Chromatic parameters of the linen samples

\begin{tabular}{ccccc}
\hline Sample & $\mathrm{L}^{*}$ & $\mathrm{C}^{*}$ & $\mathrm{DL}^{*}$ & $\mathrm{DC}^{*}$ \\
\hline $\mathrm{t} 0$ & 92.47 & 1.87 & - & - \\
$\mathrm{t} 1$ & 88.94 & 1.97 & -3.52 & 0.10 \\
$\mathrm{t} 2$ & 89.24 & 1.70 & -3.22 & -0.16 \\
$\mathrm{t} 3$ & 89.05 & 2.45 & -3.42 & 0.58 \\
$\mathrm{t} 4$ & 88.98 & 1.39 & -3.49 & -0.48 \\
$\mathrm{t} 5$ & 89.17 & 1.52 & -3.29 & -0.35 \\
\hline
\end{tabular}

All aged samples were darker and less saturated than the control sample. However, sample $\mathrm{t} 3$, which was more saturated than the control, is an exception. The visual aspect of the aged linen samples was a color shift towards a redder shade. This effect might be 
caused by the photooxidation of the linen fabrics during the ultraviolet exposure (Tera et al., 1985).

\section{CONCLUSIONS}

The accelerated weathering experiment that was performed on the linen fabrics revealed, up to a certain point, the effects of ultraviolet radiation and humidity exposure, along with relatively high temperatures. The morphology of the linen fibers was clearly affected by increasing the period of exposure inside the weathering tester, namely, extended fiber ruptures, and splits appeared. These effects have a high negative impact upon the mechanical properties of the linen textiles. At the molecular level though, the modifications imposed by the weathering conditions were not actually significant. However, the visual aspect of the linen samples was affected. The acquired information will be used as a starting point for conservation experiments.

\section{Acknowledgements}

This work was elaborated through Nucleu Program, conducted with MCI support, project no. 4N/2019/PN 191705 01. The publication fee of the paper is funded by the Ministry of Research and Innovation within Program 1 - Development of the national RD system, Subprogram 1.2 - Institutional Performance - RDI excellence funding projects, Contract no. 6PFE/2018.

\section{REFERENCES}

Akin, D.E. (2003), Kirk-Othmer Encyclopedia of Chemical Technology, John Wiley \& Sons, Inc.

Chung, C., Lee, M. and Choe, E.K. (2004), "Characterization of cotton fabric scouring by FT-IR ATR spectroscopy”, Carbohydr. Polym., 58, pp. 417-420, https://doi.org/10.1016/j.carbpol.2004.08.005.

Friedrich, K. and Breuer, U. (2015), Multifunctionality of Polymer Composites: Challenges and New Solutions, William Andrew, pp. 102-143.

Ingamells, W. (1993), Colour for textiles. A user's handbook, Hyperion Books, pp. 4-11.

Kleinert, T.N. (1972), "Ageing of Cellulose. Pt. VI. Natural Ageing of Linen over Long Periods of Time", Holzforschung, 26(2), pp. 46-51, https://doi.org/10.1515/hfsg.1972.26.2.46.

Kouznetsov, D.A., Ivanov, A.A. and Veletksy, P.R. (1996), "Effects of fires and biofractionation of carbon isotopes on results of radiocarbon dating of old textiles: The Shroud of Turin", Journal of Archaeological Science, 23, https://doi.org/10.1006/jasc.1996.0009.

Markova, I. (2019), Textile Fiber Microscopy: A Practical Approach, Wiley, pp. 31-40, https://doi.org/10.1002/9781119320029.

Tera, F.M., Abodu, L.A., Micheal, M.N. et al. (1985), A Journal of Polymer Photochemistry Part II, Vol. 6, p. 475, https://doi.org/10.1016/0144-2880(85)90034-X.

*** (2008), "Colour Terms and Definitions", Journal of the Society of Dyers and Colourists, 89(11), pp. 411422, https://doi.org/10.1111/j.1478-4408.1973.tb03113.x. 
Effects of UV, Humidity, and High Temperature Exposure on Linen Fibers

https://doi.org/10.24264/icams-2020.V.11 